\title{
Being a TEAChING ASSistant (TA) In First-YeAR Engineering Course: Perspectives, Challenges, REWARDS AND RECOMMENDATIONS
}

\author{
Jong Sook Choi \\ Ryerson University \\ jongsook.choi@ryerson.ca
}

\begin{abstract}
The CEN100 Introduction to Engineering teaching assistantship experience is examined from a TA's perspective. In addition to generic duties, CEN100 TAs are primary deliverers of the engineering design component of the course and assessors of 55\% of the course materials. Challenges faced by CEN100 TAs include changing students' perception of the course and effectively managing expectations from students and the course instructors. Also, maintaining fair and consistent grading is a big challenge to TAs. However, being CEN100 TAs has many rewards, such as improving organizational skills and public speaking skills, and obtaining real life teaching experience. Considering the degree of importance TAs play for the course, it is recommended that proper TA training is offered using available resources from the Learning and Teaching Office. Also, feedback from TAs should be rigorously collected and incorporated in CENIOO in addition to having proper TA evaluations from both students and the course instructor.
\end{abstract}

Keywords: Teaching Assistants (TA), First-Year Engineering, Course Perception, Expectation Management, Grading, Assessment, TA Evaluation, TA Feedback, TA Training

\section{INTRODUCTION}

Graduate teaching assistants (TAs) are unique in that they are simultaneously teachers, researchers, students and employees [1]. TAs have a wide range of responsibilities depending on the course and its instructor. In general, TAs supplement the course material and are there to interact with students on more of a one-on-one basis than what the professor is capable of doing in larger classes [2].

The general role of TAs in post-secondary education has a big impact on a student's learning experience [2-4]. TAs influence student retention in the sciences and engineering discipline in multiple ways. A study by [3] shows that TAs influence lab climate, course grades, and students' knowledge of science and engineering careers, all of which have an effect on students' decisions to stay in or leave the sciences.

Many universities use the first-year introductory engineering course to increase retention and undergraduate degree completion rate of qualified students $[4,5]$. For first-year introductory engineering courses, TAs serve various roles such as mentors, teachers and assessors. Also, TA's provide the "small class" feelings that some students may be more used to.

At Ryerson University, the role of TAs has significantly expanded since the course structure change implemented in 2011. The author served as CEN100 TA in Fall 2011 and Fall 2012. This paper explores unique experiences in being a TA to CEN100 from a "supplier" point of view. Section 2 describes the course and the role of TAs. Sections 3 and 4 lay out challenges faced by TAs and rewards of being a CEN100 TA, respectively. Finally, Section 5 makes recommendations for improvements.

\section{BACKGROUND}

CEN100 Introduction to Engineering is a mandatory course taken in the first semester of the first year. There is one instructor with numerous guest lecturers and eight to nine TAs, each responsible for a maximum of 120 students divided into three sections. The course consists of a two hour lecture and a one hour lab per week. The major components of the course are:

(i) Introduction to the engineering programs at Ryerson,

(ii) Orientation of the university life and policies, and of

the engineering educational requirements, and

(iii) Introduction to engineering design and management.

Prior to 2011, the course was scheduled for one hour per week and graded on a pass/fail basis [4]. However, in order to give students earlier exposure to significant problems in the engineering field to gain adequate appreciation of the issues, introduction to engineering design and management aspect of the course was 
introduced [4]. This follows the suit of many engineering schools in Canada where group project work is heavily utilized to engage first year engineering students $[5,6]$.

With the newly structured CEN100, the roles of TAs have significantly expanded as the introduction to engineering design and management component of the course is delivered by TAs through tutorials. The major course content where TAs play a significant role is technical assignments (MS Excel in Fall 2011 and MATLAB in Fall 2012), an engineering disaster project, and reverse engineering project. They account for $55 \%$ of the total grade. The significance of the TAs role is obvious as nearly half of the course content is delivered by TAs and a third of the time is spent with TAs. Also, TAs serve a crucial role of being the gateway between students and professors.

The roles of the CEN100 TAs are divided into the following categories: grading, delivering tutorials and student management.

(i) Delivering tutorial materials: Project managements, MATLAB, MS Excel, etc. Tutorial slides are prepared by the instructor.

(ii) Grading: Each project consists of a proposal, progress report, final report and presentation. Also, there are three technical assignments.

(iii) Student management: TAs deal with the day-to-day problems via email communications. Therefore, TAs manage project groups and are the initial line of contact for conflict management.

\section{CHALLENGES}

There are many challenges to teaching and administering any course. When it is a first year course with nearly 1000 students, challenges are even greater. Even simple oversight can cause a stressful situation for students as well as instructors. In CEN100, TAs face distinct challenges because the unique nature of the course.

\subsection{Course Perception}

There are two perception issue associated with CEN100 Introduction to Engineering. One is related to having a non-theoretical course among many mathematics and sciences courses. The other is related to the previous structure of the pass/fail nature of the course.

It is a not-so-well-kept secret that many students question the real value of the first year engineering design course in the myriad of theory driven courses. Many students are under the assumption that CEN100 is not an important course and that it does not have any meaningful practical value. Based on such an assumption, many are adamant that CEN100 should be a very easy course and a definite grade-booster.

Such an ill-conceived notion results in too many students considering the course as just a degree requirement, nothing more, nothing less. Therefore, it is common to see students making a conscious decision to focus on their more "important" courses than CEN100, especially during the exam time. Unfortunately, the author has seen too many students who cry foul when they realize that CEN100 involves real work.

Some of the basis for such a perspective is what students hear from others in previous years who had already taken the course. However, the fundamental challenges lie in the high degree of difficulty in changing a student's perception of the pass or fail structure of the course that has developed over the years.

Although the implemented course structure change was supposed to mitigate this issue, the author encountered students' skepticisms throughout the semesters. It was very difficult to change the students' perception even with repeated reminders of the new course structure and its importance. In fact, there was a tremendous pressure from students to agree with them on the less than flattering course perception. It was up to each TA to fend off such pressure using positive attitudes and wits.

It is very interesting to note, however, that the greatest degree of success the author had with students with regard to the course perception issue was through relating the author's professional industry experience as a practicing engineer to the course component. Based on such experience, it is clear that TAs have a critical role in changing students' perception of the course.

\subsection{Expectation Management}

CEN100 TAs have many expectations bestowed upon them. In addition, CEN100 TAs make certain assumptions regarding their responsibilities and their roles. Managing such expectations from various sources is difficult to say the least.

In CEN100, students expect the course to be wellmanaged, requirements to be clearly explained and questions to be answered instantaneously. They assume that the course will have a far smaller work-load than their other courses and that they will get decent grades. Most important of all, since most students neither know nor understand the hierarchical nature of the relationship between instructors and TAs, they apply the exact same standards to instructors and TAs.

The instructor rightly presumes that TAs will deliver tutorials in an effective manner. The instructor also relies on TAs to grade fairly and with a high degree of consistency. Also, it is expected that TAs will manage trivial problems such as answering basic questions and 
provide a first line of support if there are problems arising from group projects.

TAs assume that everything that is needed to fulfill such expectations is clearly defined by the instructor with detailed rubrics because CEN100 TAs are not responsible for the content of the course. Also, TAs expect that since first year students got into engineering, they must be smart enough and know enough to understand the TAs most of the time.

However, reality is far from such rosy expectations. First, logistics challenges to a completely revamped 1000student course in its second year running are insurmountable. There always is something that course providers did not foresee. Not everything will be perfect.

Second, TAs must deal with the reality that although they did not design the course, they must answer all the questions from students. In other words, TAs are they gateway between professors and students. For example, conflict management in group works are the most complicated and difficult to handle. Currently, TAs only give recommendations to the instructor regarding project group issues but TAs have to provide the first line of support.

Third, the truth with first year engineering students for that matter with anyone an individual works with - is that they know a lot. Unfortunately, they have critical gaps in their knowledge preventing them from understanding certain crucial concepts. For example, the author was confounded that the students could not understand the concept of "milestones" after giving textbook definitions with supplemental explanations. Yet, the author had to ask students what the Prezi, a presentation tool, was when they asked for the permission to use it for their project presentation. It is a simple example but it illustrates the point that it is not that students know less than TAs, they know different things than TAs.

\subsection{Grading}

Although each TA is expected to grade students' work with a high degree of consistency and fairness, TAs have encountered difficulties in meeting such an expectation. Marks have varied widely from one TA to another each term. The most common issue encountered was awarding unreasonable high average marks with very low variance on major technical reports when the quality of work does not warrant such grades.

Unfortunately, most engineering TAs are not familiar with grading technical reports even with a rubric. In fact, many TAs do not know the difference between a rubric and a grading scheme. Even more aggravating for TAs is to provide useful feedback to students. The most common responsibility of engineering TAs is grading lab reports. However, the focus of lab reports is completely different from that of technical reports and they tend to weigh far less.

\subsection{Varying TA Qualifications}

Considering the important role TAs play in delivering CEN100, varying qualifications of TAs are a huge challenge to the course. How effectively tutorials are delivered is entirely dependent upon TAs. CEN100 TAs have varying backgrounds, nationalities, and cultures. Many, including the author, have not completed their undergraduate degree at Ryerson University and had no prior exposure to the course. Also, some TAs have limited understanding of the Canadian engineering education system and cultures. This has a huge impact on students' interaction with the TAs as students themselves are from many different cultures. In addition, for some TAs language can be an issue. When it is compounded with presentation and public speaking skills, it can easily overwhelm TAs as well as students.

\section{REWARDS}

There are many rewards for being CEN100 TAs although the author found CEN100 to be more difficult and to contain a greater workload in comparison to other engineering courses. First is how TAs get to improve their organizational skills and put them into practice. One may argue that any improvement in organization skills was made out of necessity but such skill is not something one just forgets. Second is enhanced public speaking skills gained through delivering tutorials and having to present to students. Third is having an opportunity to experience a real-world teaching environment through running tutorials and managing students in multiple ways. Finally, because TAs deliver the engineering design portion of the course, TAs have a good refresher of project management theories.

\section{RECOMMENDATIONS}

CEN100 is only in its second year of running. Surely, there are many recommendations and suggestions for improving the course from tighter schedule management to providing even more engaging group projects to students. They are well documented in $[5,7]$ as such recommendations are not exclusive to CEN100. For challenges described in Section 3, the following recommendations are provided.

\subsection{TA Training}

The importance of TA training has been highlighted in $[3,7,8]$. This is especially true for CEN100 as TAs face 
numerous challenges in administering, teaching and assessing the course. Considering the important role a TA plays in CEN100, TA training would be very helpful. Many professional development teaching courses available for TAs are provided by the Learning and Teaching Office (LTO) at Ryerson including multicultural classroom management, tutorial planning and conflict management. It would also be highly beneficial to work with LTO to develop a course for CEN100 TAs regarding grading technical reports and providing useful feedback.

\subsection{Feedback from TAs}

Feedback from TAs should be rigorously collected and incorporated in CEN100. Considering that a third of the course components is almost exclusively delivered by TAs, feedback from TAs would play an invaluable role in improving the course content to suit the needs of everyone involved. In addition, since students spend a third of their contact hours with TAs who provide the first line of support to students, TAs may be able to catch any useful feedback from students which never make it back to the course evaluation. For example, students are less likely to remember recommendations for the materials covered at the beginning of the semester in comparison to the end of the semester. Also, students are more likely to voice their opinions to TAs in forms of complaints rather than write them out on a generic course evaluation form.

\subsection{Feedback to TAs}

Feedback is a collaborative effort and there is a distinct relationship between giving and receiving feedback. Proper TA evaluations are very valuable to gage each TA's performance and identify any shortcomings [7]. The feedback should be two-fold, taken from students and the course instructor. Currently, no formal system exists for CEN100. At Ryerson, TA evaluations are departmentspecific and tend to be generic. Again, considering the importance of the TA's role in the course, a proper feedback system should be set up and actively communicated.

\section{CONCLUSIONS}

The CEN100 Introduction to Engineering TA experience has been examined from the TA's perspective. With the newly structured CEN100, the roles of TAs have significantly expanded as the TAs are responsible for delivering and assessing $55 \%$ of the course content and a third of students' contact hours is spent with a TA. Also, TAs serve a crucial role of being the gateway between students and professors.
Challenges include changing a student's perception of the course and effectively managing expectations from students, the course instructors and TAs. Other challenges are fair and consistent grading and dealing with varying qualifications of TAs.

Although CEN100 is not the easiest course to manage as a TA, it has many rewards. They include improving organizational skills, public speaking skills, real life teaching experience and review of project management theories.

Considering the important roles TAs play for the course, it is recommended that proper TA training is done using available resources from the LTO. Also, Feedback from TAs should be rigorously collected and incorporated in CEN100 in addition to having proper TA evaluations from both students and the course instructor.

\section{Acknowledgements}

The author thanks Dr. L. Amleh, Department of Civil Engineering, Ryerson University, for her generous support and guidance for writing this paper.

\section{References}

[1] V. Muzaka, "The niche of graduate teaching assistants (GTAs): perceptions and reflections," Teaching in Higher Education, vol. 14, no. 1, pp. 1-12, 2009.

[2] M. Dudley, "Jumping out of an airplane: a TA's perspective on teaching effectiveness," Eastern Educ J, vol. 38, pp. 110, 2009.

[3] C. O'Neal, M. Wright, C. Cook, T. Perorazio, and J. Purkiss, "The impact of teaching assistants on student retention in the sciences: Lessons for TA training." Journal of College Science Teaching, vol. 36, no. 5, pp. 24-29, 2007.

[4] L. Amleh and M. Lachemi, "Work in progress- addressing first year engineering retention through focused educational programs supporting student success," in EDULEARN11 Proceedings, 3rd International Conference on Education and New Learning Technologies, IATED, July 4-6, 2011, pp. 2569-2577.

[5] J. Bazylak and P. Wild, "Best practices review of first-year engineering design education," Proceedings of the Canadian Engineering Education Association, 2011.

[6] N. A. Pendergrass, R. E. Kowalczyk, J. P. Dowd, R. N. Laoulache, W. Nelles, J. A. Golen, and E. Fowler, "Improving first-year engineering education," Journal of Engineering Education, vol. 90, no. 1, pp. 33-41, 2001.

[7] C. Park, "The graduate teaching assistant (GTA): lessons from North American experience," Teaching in Higher Education, vol. 9, no. 3, pp. 349-361, 2004.

[8] D. M. Shannon, D. J. Twale, and M. S. Moore, "TA teaching effectiveness: The impact of training and teaching experience," Journal of Higher Education, pp. 440-466, 1998. 